\title{
The effect of public surveillance cameras on crime clearance rates
}

Yeondae Jung ${ }^{1} \&$ Andrew P. Wheeler ${ }^{1, *}$

*Corresponding author, email: apwheele@gmail.com

1. School of Economic, Political, and Policy Sciences

The University of Texas at Dallas

800 West Campbell Road, Mail Station GR 31

Richardson, Texas 75080-3021

Yeondae Jung, MS, is a PhD student of Geospatial Information Science at the University of Texas at Dallas. He received an MS on criminology from Dongguk University at Seoul, Korea. His research interests are geospatial analysis of crime and crime prevention.

Andrew P. Wheeler is an Assistant Professor of criminology at the University of Texas at Dallas in the School of Economic, Political, and Policy Sciences. His research focuses on the spatial analysis of crime at micro places and practical problems faced by crime analysts. 


\title{
Title: The effect of public surveillance cameras on crime clearance rates
}

\begin{abstract}
Much research has examined the crime reduction benefits of public close-circuit television (CCTV) cameras, suggesting that cameras may not deter enough crime to justify their cost. Another benefit of CCTV though is its utility in investigations and in clearing cases, which has been much less studied. Using a sample of public crimes and case clearances in Dallas, Texas, we examine the efficacy that public CCTV cameras increase case clearance rates using a pre-post research design. We find that cases closer to cameras did have an increased clearance rate after the cameras were installed in Dallas. But the effects faded quite quickly in space, and were mostly limited to thefts. While our estimates here suggest the cameras are likely not cost-effective in this sample in terms of increasing clearances, it suggests there is potential to be more targeted in camera placement that might provide better justification for their (limited) use.
\end{abstract}

Keywords: CCTV, crime-clearance, arrests, deterrence, police-technology

\section{Introduction}

Over the last few decades, closed circuit television (CCTV) monitoring public places has been implemented around the world. Development of information technology facilitates public surveillance with continual improvements in higher resolution video and cheaper data storage for CCTV footage. Yet, it still costs a significant amount of money to install and maintain surveillance systems, not to mention potential infringements of privacy that come along with CCTVs.

In criminology, CCTVs have been widely studied in relation to situational crime prevention (Clarke, 1997). Because the theory expects increased level of guardianship will lower the opportunity for crime, researchers have investigated to find deterrent effects of CCTVs (Piza et al., 2019; Welsh \& Farrington, 2008, 2009). The main question has been whether crimes are reduced nearby cameras after they are installed. Results from those studies show that CCTV's do reduce crime (Piza et al., 2019), but such crime reductions do not unambiguously justify their cost (Piza et al., 2016; Ratcliffe \& Groff, 2019).

What has been less focused on, however, is the effectiveness of CCTVs in crime clearance. CCTV may help police to detect crimes and arrest offenders in progress by real-time monitoring (Piza et al., 2014), as well as find possible suspects by examining video footage after a crime has occurred (Ashby, 2017; Morgan \& Dowling, 2019). Clearance of crime is also important for crime prevention because it can contribute to crime deterrence by capturing offenders who may have committed additional crimes, and 
increase the perceived risk of apprehension for potential offenders. Moreover, the clearance rate may indicate police effectiveness (Cordner, 1989), which means a high rate of uncleared crimes may decrease public trust in law enforcement organizations (Tankebe, 2008). Thus, if CCTVs increase the probability of clearing crime incidents it may better justify their cost in conjunction with their effects on crime reduction.

This study will address the effectiveness of CCTVs in the context of crime clearance using data on reported crimes and public CCTV in Dallas, Texas. Specifically, it will address the three questions below:

1. Is there a difference in crime clearance before and after CCTV installation?

2. Is the difference in clearance rates related to the distance to the nearest CCTVs?

3. Do cameras increase clearance rates across equally all crime types?

To answer those questions, this study will use a pre/post quasi-experimental design (Campbell \& Stanley, 2015), where variables which can have impact on crime clearance will be controlled to discern the effect of CCTVs on crime clearance. Using data on 329 camera installations in Dallas, Texas, we show how after cameras are installed, crime clearances nearby cameras increase by a small margin, but only do so for a short distance from the camera. When examining clearance changes across crime types, the increases are mostly limited general thefts. In total, while this provides evidence in line with past research that CCTV does increase clearance rates (Ashby, 2017; Piza et al., 2014), the overall effect is likely not sufficient to justify the cost of the cameras as currently used in Dallas.

\section{Effects of CCTVs}

The most widely studied topic for CCTVs is their deterrent effects on crime. In their meta-analysis on 80 selected studies, Piza, Welsh and Farrington (2019) found that the introduction of CCTVs is related to a modest but significant reduction in crime. They also report that CCTVs are consistently effective in decreasing crime in parking lots and residential areas as well as other location types. By crime type, CCTV is associated with significant reductions in vehicle crime, property crime and drug-related crime, however, there were no significant effects observed for violent crime or disorder. These are consistent findings with earlier reviews of CCTV studies (Welsh \& Farrington, 2008, 2009).

Meanwhile, some other researchers also emphasize the need of cost-benefit analyses on CCTV effects, because running a surveillance system requires significant amounts of money and resources for equipment installation, personnel training, and system maintenance (Lin \& van Gulijk, 2014). Local government officials should also consider opportunity costs, since these resources could have been used for other promising crime prevention projects (Roman \& Farrell, 2002, pp. 80-81). Therefore, the benefits of CCTV should exceed the cost of installation and maintenance for running the surveillance system. Piza, Gilchrist, Caplan, Kennedy and O'Hara (2016) argued that a proactive CCTV system can be cost effective for 
agencies with pre-existing CCTV infrastructure because they found the cost benefits in the Newark CCTV Directed Patrol strategy were more than $\$ 6.99$ for every $\$ 1$ invested.

People's perception should also be accounted for while considering cost and benefit of CCTVs. Numerous studies have suggested concerns on potential infringement of privacy by surveillance cameras (Goold, 2002; Lippert, 2009; Möllers \& Hälterlein, 2013; Taylor, 2010; Wilson \& Sutton, 2004). However, literature finds that public attitudes toward CCTV installations are generally positive because people expect CCTV can help prevent crime (Bennett \& Gelsthorpe, 1996; Ditton, 2000; Phillips, 1999; Spriggs et al., 2005; Wells et al., 2006). In that sense, the benefit from lower fear of crime is greater than the cost of possible infringement of privacy, at least to general public (Bennett \& Gelsthorpe, 1996; Honess \& Charman, 1992). On the other hand, further studies on the effect of CCTVs on feeling safe may imply less supportive attitudes. Ditton (2000) reported that feelings of safety are not significantly improved after the installation of CCTV cameras even though respondents expected less fear of crime before actual installation. Gill and colleagues (2007) also reported similar results in that residents become indifferent to CCTVs after they are installed.

Compared to the extensive discussion on the deterrent effect of CCTVs, their use in crime investigations have been less studied. A few studies suggest that CCTVs are one of the resources that police use to detect and solve crime cases (Coupe, 2016). Piza, Caplan and Kennedy (2014) compared the arrest rates of crime cases which are detected by CCTV monitoring and those which are reported by calls-forservices (CFS). They find that the arrest rates of incidents initiated by CCTV are more than twice that of the expected rates, and the closure rate is also higher than the expected rates. Coupe and Kaur (2005) reported that there were more than two and half times of non-residential burglary detections where CCTVs were installed than at premises with no CCTV cameras and the difference is especially obvious in crimes during nighttime hours. Ashby (2017) examined 251,195 crime records by British Transport Police and reported CCTVs were available in $45 \%$ of cases and judged to be useful for the investigation in $65 \%$ of the cases where it was available. Morgan and Dowling (2019) investigated the records CCTV footage requests managed by Sydney Train Agency to compare the solution rate between the cases where video was requested and provided, and the cases where video footage was requested but not provided. They reported that the former is significantly more likely to be cleared by legal action than the latter. Even though the latter two studies are limited to offenses on railways, their results suggest CCTVs could be promising as investigative tools for various types of crime. On the contrary, Paine (2012) found that CCTV footage preservation at the crime scene brought no statistically significant difference in solution rates for both completed and attempted burglaries.

\section{Crime Clearance}


Clearance of a crime can be affected by the characteristics of the crime itself as well as neighborhood characteristics where the crime occurred. According to Black's behavior of law theory (1976), it is because these characteristics generally affect the discretional decision-making of the police handling the cases. At the incident level, demographic characteristics of victims and situational characteristics of crime may influence the likelihood of clearance (Roberts, 2008). Black (1976) suggests that victimization of lowerclass victims may not be treated as favorably as those with higher-class victims because lower-class victims are more likely to be devalued in the legal system. Similarly, crime incidents with younger, female and ethnic minority victims are expected to be less cleared (Roberts, 2008). The results of Bynum, Cordner and Greene's study (1982) supports this idea in that burglary victims from higher-economic areas of the city were more likely to receive favorable investigative treatment, while minority victims of property crimes are likely to receive less favorable treatment, although the effect is weak. Briggs and Opsal (2012) also note that race and ethnicity of the victim are related to police clearance of cases. On the contrary, Gottfredson and Hindelang (1979) argue the seriousness of crime is a more valid predictor of legal outcomes, including crime reporting, arrest, and prosecution, than other factors, such as victim status or relational distance to the victim. According to Gottfredson and Hindelang, more serious types of crime, such as violent crime, should be more likely to be cleared than a crime without a victim injury.

In the context of neighborhood, social disorganization theory (Shaw \& McKay, 1942) can also present factors related to crime clearance. Borg and Parker (2001) report the homicide clearance is higher in cities with higher educational expenditure and attainment, greater residential stability and lower rates of homicides. On the other hand, some research shows legal cynicism and less willingness to cooperate to police are related to low economic status and high minority constitution of neighborhoods (Bell, 2016; Carr et al., 2007; Nivette et al., 2015). Extending social disorganization theory, Sampson and colleagues (1997) developed the idea of collective efficacy, which represents the perceived effectiveness of informal social controls by which residents themselves achieve public orders. Thus, residents living in areas with high collective efficacy may lobby the local police department to solve the community's crime problem at least by arresting offenders and increasing the clearance of the occurred crime. Collective efficacy is also reported to mediate the association between legal cynicism and the probability of arrest (Kirk \& Matsuda, 2011).

On the contrary, the availability of evidence in crime clearance is often underemphasized because it seems too obvious. Since Black's provocative theory (Black, 1976), many researchers have tried to examine the effect of individual/situational/neighborhood factors of crime in the law enforcement process, including investigative decision-making, while omitting the existence of physical evidence (Briggs \& Opsal, 2012; Bynum et al., 1982; Kirk \& Matsuda, 2011) or using the it as a control variable (Roberts, 2007, 2008). Recent studies on physical evidence suggest somewhat disappointing results of its effect on crime clearance. 
Baskin and Sommers $(2010,2011)$ argue that none of their forensic evidence variables significantly influenced criminal justice outcomes of homicides or burglary. McEwen and Regoeczi (2015) also reported that forensic evidence (other than eyewitness reports) generally are not associated with case closure. Kutaleladze, Lawson and Andiloro (2015) found that physical evidences increases the probability of prosecution in felony drug cases, but only the recovery of currency influences the sentencing outcomes. On the other hand, while surveillance cameras can also be utilized as one piece of physical evidence, it has rarely been studied in the literature investigating crime clearance.

In sum, the prior literature reveals a gap on the association between CCTV effects and crime clearance. While several prior studies have examined this when restricting to cases in which other administrative markers noted the cameras were used in an investigation (Ashby, 2017), or caught footage of the crime in the act (Piza et al., 2014), these restrictions may overestimate the effect of cameras on crime clearances in general. CCTV is not utilized in a vacuum, and there are other operational constraints, such as detective time (Braga \& Dusseault, 2018), that may impact the efficacy of the cameras in relation to clearing crimes. Thus, our study uses an experimental design to test the overall effect that cameras had on crime clearance rates after they were installed in Dallas. While this is a weakness in one sense, we do not have access to external information when the cameras were utilized, it is a strength in another: ultimately the cost-benefit of the cameras should be weighed in relation to how effective they are in clearing all crimes that occur nearby where they are installed, not just incidents in which they were selectively used. Using a large sample of crime incidents allows us to quantify this overall effect fairly precisely, and thus provide better evidence overall for whether the cameras are worth their cost in practice.

\section{Methods}

\section{Data}

This study used the public police incident data retrieved from the Dallas OpenData (https://www.dallasopendata.com/). Dallas police department has been publicizing the Record Management System (RMS) data since June 1, 2014. To protect privacy concerns, some types of offenses are filtered in the provided data: 1) sexually oriented offenses; 2) offenses where juveniles or children are victim or suspect; 3) social services referral offenses.

For analysis of this study, duplicate incidents with the same incident ID numbers were suppressed to one record by priority of arrest information and seriousness of the crime type. Thus, a case record with updated information of arrest and more serious crime was preferentially selected as the representative case among the duplicated incidents. The seriousness of crime was decided in order of murder, rape, robbery, assault, burglary, motor vehicle theft, theft, arson, drug, and weapon. Crimes which are not assigned to those categories, such as minor violations, were excluded from the final data set. 
The study period was set at four years from June 1, 2014 to May 31, 2018 by report date of crime. As data was retrieved in January 2019, the last reported case in the data occurred in more than seven months

prior at the point of the data retrieval so that the clearance information could have been updated for seven months after the occurrence of the last case. The resultant number of cases is 201,315.

Public CCTV installations were obtained directly from the Dallas Police Department. The data contains the location information and month of installation. The present CCTVs were installed in three stages: August 2014, May 2016 and November 2017. Duplicate data with the exact same installation and location information was also suppressed to one. The resultant number of CCTVs is 329.

Since the study connects crimes and CCTV in pre/post-installation setting, the vague information of CCTV installation month can be misleading. Therefore, we also exclude crimes which occurred in the month of CCTV installation. Therefore, the final data set with relevant CCTV connections is 175,846 police incidents.

\section{Variables}

The unit of analysis is the police incident. The data includes the following variable information.

\section{1) Response variable: Clearance of crime}

Clearance is a binary response variable recoded based on the 'Offense Status' in the original data. The items of 'Clear by Arrest', 'Clear by Exceptional Arrest', 'Closed/Cleared' are coded as 1, and the rest ('Open' and 'Suspended') are coded as zero. The clearance information is presented in Table 1.

[Table 1 goes about here]

In the given data, 17,862 (10.2\%) cases are cleared, while 157,984 cases remain uncleared (89.8\%). Most cleared cases are by arrest and exceptional arrest (99.6\%) and most uncleared cases are suspended ones $(98.7 \%)$.

\section{2) Covariates}

\section{CCTV coverage and spline distance}

Distance between a crime location and the nearest CCTV is measured by feet using the Euclidian method. The measurement is based on the current location of the CCTV at the time of the study. That is, a crime occurring before installation of the nearest CCTV will get the imaginary distance to the CCTV which did not exist at the time of the crime occurrence. 
In this study, distance from crime to CCTVs will be incorporated in the regression model using restricted cubic spline basis functions. Splines are similar to polynomial regression (e.g. including squared and cubic terms of regressors on the right hand side), in that one distance term is turned into several new variables, allowing the functional form of the distance effect (Marsh \& Cormier, 2001), but tend to be more robust in the tails of the function than polynomial terms (Harrell, 2015). Each spline term represents membership in a certain range of distance so that the overall prediction will show smooth fitted values instead of abrupt changes of slope by membership.

We assume that there may be distinct pattern changes in CCTV effects on clearance probability according to the CCTV coverage. Unlike prior work though, this does not restrict the effect to a particular buffer or viewshed of the camera (Ratcliffe \& Groff, 2019). Even if a crime does not initially occur within the viewshed of a camera, a suspect may travel into the viewshed before or after a crime, which could still be instrumental in clearing the case. Such ancillary information is more likely to occur nearby a camera however, and so we model the probability of a case being cleared as a non-linear function of the distance to the nearest public CCTV. Corresponding to the prior criteria of grouping CCTV coverage, the knot locations for constructing the splines are set at 500, 1000, 1500 feet (see Ratcliffe, Taniguchi \& Taylor (2009) and Lim \& Wilcox (2017)). The distribution of the distance between a crime location and the nearest CCTV is presented in Table 2.

[Table 2 goes about here]

\section{Pre/post installation}

In crime-CCTV pairs, a case is coded 0 if it occurred before installation of the nearest CCTV, and 1 if occurred afterwards. This way of coding aims to incorporate pre/post installation effects by including the interaction term between distance to camera and pre/post dummy. A total of 71,446 cases (40.6\%) occurred before installation of its nearest CCTV, while 104,440 cases (59.4\%) occurred after installation of its nearest CCTV.

\section{Interaction between pre/post installation and spline distance}

Interaction terms are added to the model specification assuming that the effect of CCTV installation on crime clearance will vary according to the distance to the nearest CCTV. For example, installation of a CCTV may increase clearance rates in areas monitored by CCTVs while it may have a lesser effect in buffer and control areas. If clearance rates increase regardless of the distance, the increase may not be attributable to the installation of CCTVs. Additionally, this may provide evidence of displacement of investigative effort associated with the cameras. If the crime clearance goes up nearby cameras, but decreases further away from cameras (relative to the pre-camera trends), it may indicate detectives spend more time on 
incidents that are now aided by the cameras, but overall do not clear more crimes than prior to the cameras installation.

\section{Type of crime}

Cases are categorized by crime type because serious crime or other specific crime types may be treated more intensively and may have higher clearance rates (Gottfredson \& Hindelang, 1979). Or, some types of crime may be more likely to be cleared with video footage evidence (Coupe, 2016; Coupe \& Kaur, 2005). The crime type contained in the data set is originally coded based on UCR and NIBRS, and they are recoded to 10 crime types: murder, rape, robbery, assault, burglary, motor vehicle theft, theft, arson, drug, and weapon. However, since Dallas PD does not publicize rape crime data, the final data set actually contains nine crime types (Table 3).

[Table 3 goes about here]

\section{Report year}

Police enforcement and investigative practices may reflect temporal trends, such that police are more driven by the push for higher clearance of crime or by emphasis on human rights related to less aggressive arrests and investigations. The linear trend of clearance will be represented by the year variable. To avoid seasonal effects, the time point is classified by year which starts on June 1 each year. Over the study period, clearance rates in Dallas have been going down overall, from $11.1 \%$ in year 0 to $10.0 \%$ in year 3 .

[Table 4 goes about here]

\section{Interval between report date and crime occurrence date}

The interval between report and occurrence of crime can influence clearance rates. Possible evidence may be lost, recall of complaints may become incorrect, and CCTV video footage may not be available in cases where the record was overwritten due to lack of storage capacity. To control these factors, the interval between report and crime occurrence is included in the model measuring the number of days between the most recent occurrence date (in case of sequential crime) and the report date. Most cases were reported immediately on the last day of occurrence $(83.1 \%)$ or within 30 days $(99.2 \%)$.

\section{3) Random effects: Census block group membership}

Census block group membership is included as a random effect indicator in the mixed model specification. Even though previous literature pointed out that neighborhood settings can influence to clearance rate, those settings are not the focus of interest here. Therefore, this study tries to control the 
effect of neighborhood in the random effect term assuming crimes in the same block group will be influenced by the same unspecified nesting effect from the neighborhood. The total number of block groups is 956 in the given data set.

\section{Analysis}

A generalized linear mixed model was chosen to incorporate both pre/post installation and distance between the crime location and the nearest CCTV, also considering the geographical context (Gelman \& Hill, 2006). Since the question of interest is whether CCTV effects on crime clearance are different by distance to CCTV, the model will also include the interaction term between pre/post installation and distance to crime, which will be incorporated into the regression as spline terms. In the model specification, three variables were also included to control the confounding effects: interval between report date and crime occurrence date, report year, and crime types. Since the dependent variable is a binary response, the suggested model will use logistic specification. Therefore, the overall model will be specified as follows:

$$
\operatorname{Pr}\left(y_{i j}=1\right)=\operatorname{logit}^{-1}\left(\boldsymbol{x}_{i j}^{\prime} \boldsymbol{\beta}+b_{j}\right), i=1, \cdots, n_{j} \text { or } 0, j=1, \cdots, J
$$

where $y_{i j}$ is a binary response of clearance of observation $i$ in block group $j, \operatorname{Pr}()$ is a probability function, $\operatorname{logit}^{-1}()$ is an inverse of logit function specified as $\operatorname{logit}(x)=\frac{x}{1-x}, x_{i j}^{\prime}$ is a row vector of covariates (including one for the intercept), $\boldsymbol{\beta}$ is a vector of parameters to be estimated, and $b_{j}$ is a random effect determined by membership of block group $j$. Each block group has a different number of observations $\left(n_{j}\right)$. $J$ represents the total number of block groups. The model specification implies that the probability that response is equal to one will be determined by the inverse logit of the given fitted effects and areal random effects.

In several ways, fitting the suggested model in this study will be different from the usual regression process. First, the non-linear association between the response and the covariates impede intuitive interpretation of the covariates' effects. The usual practice of using logit can be misleading for interpreting the original relationship between covariates and the probability, and can even introduce bias. Mood (2010) warns that omitted variables which should have been included model can be more problematic in logistic regression than linear regression. While omitted variables in linear models which are not correlated with the existing variables do not harm estimation of parameters, parameter estimation in a logit model with omitted variables can be biased no matter whether the omitted variables are correlated or not. Mize (2019) informs that the relationships between covariates and the original response of probability is unstable. Using simulated data, he demonstrates the same model specification can lead to different relationships between 
covariates and probability responses according to the range of the covariates. Therefore, for presenting the analysis of binary response, Mood suggests interpreting the change of probabilities such as marginal effects, while Mize advocates the use of visualization methods instead of interpreting the coefficient of covariates on logit response.

The second complication comes from the assumption of nonlinear effects of distance to nearest CCTVs. Because we assume some pivotal changes of distance effects on the probability of clearance by CCTV coverage, we use spline basis to model the effect of distance, instead of a single distance coefficient. Since adding spline terms enables the modeling of non-linear relationships between covariates and response, the relationship between distance and clearance rate will have different patterns according to the range of distance. Although the spline terms work better for the interest of this study, it will also add complexity in statistical inference of the individual parameters. Because spline terms represent the strength of membership in each knot of distance rather than actual increase of distance, interpretation of variable effects is not intuitive, and so we rely on graphical methods to show the non-linear distance to nearest camera effects, and how those change from pre-to-post camera installation.

Lastly, random effects by census block group is another source of model complexity in the analysis of this study. Some cases may be more likely to be cleared than others due to the condition of the community where the crime takes place. The random effects in the multilevel specification are included in the model to control the grouping effect by block groups so that a case observation within a certain block group will be less correlated with other observations from the same block groups. In addition, random effect terms will also surrogate local conditions influencing the probability of clearance, which will not be specified in this study. Thus, the predicted logit response from the model will reflect the varying intercept by block groups, and its effect on the predicted probability will add more complexity to interpret the result.

Overall, standardized statistical process and inference based on significance of estimated parameters may not provide a straightforward interpretation or may even suggest incorrect conclusion on the effect of variables on the original probability response. Therefore, this study will investigate a change of probabilities by pre/post conditions with corresponding confidence intervals at each point of CCTV distance. Calculation of confidence intervals uses Hummel-Wiseman method (Hummel \& Wiseman, 2008). According to the method, the variance of $p_{\tau}$, for $\tau=0,1$ asymptotically can be constructed as

$$
\operatorname{Var}\left(p_{\tau}\right)=\operatorname{Var}\left(u_{\tau}\right)\left[p_{\tau}\left(1-p_{\tau}\right)\right]^{2}
$$

where $u_{\tau}$ is defined as log-odds of $p_{\tau}$. Therefore, treating $u_{1}$ and $u_{0}$ as independent estimators, the variance of changing probability is given by: 


$$
\operatorname{Var}(\Delta p)=\operatorname{Var}\left(p_{1}\right)+\operatorname{Var}\left(p_{0}\right)
$$

where $\Delta p$ represents the difference of probability in $p_{1}$ and $p_{0}$ (Reeve, 2018). Prior literature suggests various method to visualize the predicted probability with confidence interval (Mize, 2019; Mood, 2010).

We additionally use these estimates in the changes in probability of case clearance to calculate the expected increases in the number of arrests that occurred post camera installation, as these will be the most useful in cost-benefit analysis of the efficacy of the cameras. For a simplified example, imagine a camera increases the probability of an arrest by $10 \%$, and 100 crimes occurred around the camera. The expected increase in the total number of arrests is 10 based on the installation of the cameras. So, this effect is a function of the increased probability of a clearance and the number of crimes that occur around a camera.

\section{Results}

The simple method to detect CCTV effect on case clearance is using descriptive plots. The clearance rate is calculated by the scheme of CCTV coverage level as used in the literature (Lim \& Wilcox, 2017; Ratcliffe et al., 2009). Thus, cases occurred at a distance of zero to 500ft from the nearest CCTV were grouped as "Target", cases occurred at a distance of $500 \mathrm{ft}$ to $1000 \mathrm{ft}$ as "Buffer", and cases occurred at a distance of $1,000 \mathrm{ft}$ to $1,500 \mathrm{ft}$ as "Control".

Figure 1 reports clearance rate increased more at the areas covered by CCTV surveillance while general increase of clearance rates is seen within the distance of 1,500 ft from CCTVs. The vertical bars represent $95 \%$ confidence interval for statistical significance. The graph indicates that the clearance rate in the targeted areas increased significantly after installation of CCTVs while the buffer areas and the control areas show smaller increases in clearance rates. This is despite overall clearance rates have been decreasing citywide in Dallas over the study period. This also shows that cameras are placed in areas with higher clearance rates to begin with.

[Figure 1 goes about here]

[Table 5 goes about here]

Table 5 reports the result of multi-level logistic regression using spline distance. The intercept represents the logit of a case where all independent variables are zero, as well as the average random intercept for block groups. Thus, estimated clearance rate when a crime is reported between June 1, 2014 and May 31, 2015, without any delay after occurrence, before installation of the nearest CCTV, and right at the location of the CCTV is about $10.9 \%$ [OR/(1-OR)]. 
The negative coefficient of report year indicates general decline of clearance rates by year. Clearance rates also decrease as the interval between occurrence and report increases. While Post CCTV installation, spline distance, and their interaction generally show significant effect on clearance rates, direct interpretation of their effect can be misleading. First, the coefficient of Post CCTV installation does not necessarily indicate the direct effect of CCTVs, but should be understood in relation to other interaction effects. We do not expect CCTV will influence to clearance rate regardless of its distance to crime. Second, the spline terms do not represent the increase of distance but the strength of membership by spline knots.

The left of Figure 2 shows the conditional plot based on the model specification of Table 5. The predicted clearance rates are determined by spline distance and CCTV installation assuming that the report year and the interval to crime report are on their mean values. The graph clearly shows the increase of clearance after CCTV installation at area near to CCTV, while clearance is lowered or less increased after CCTV installation as CCTV spline distance becomes longer. The right side of Figure 2 shows the difference of clearance after installation of CCTV with its $95 \%$ confidence intervals. The graph indicates that the area within 500 feet from nearest CCTV have significant increase of clearance rates after installation of nearest CCTV, while the difference is insignificant at further distance ranges.

[Figure 2 goes about here]

Next, we mapped the random effects which show neighborhood effects on crime clearance. Figure 3 shows random effects by block groups. The random effects are used to capture the unexplained effect of community which is usually measured by block group. The missing values of random effects are due to no crime within those block groups. The Moran' I value (Moran, 1950) of the random effect excluding missing values is low, but significant $(\mathrm{MC}=0.09, \mathrm{p}<0.001)$. There is no clear pattern in the random effects that suggests a simple relationship such as certain neighborhood factors are associated with increased clearance rates in Dallas, although it appears in general more commercialized areas tend to have higher clearance rates.

[Figure 3 goes about here]

Next, we precede to investigate if each crime type agrees to the pattern of clearance found in Figure 2. Figure 4 lists the expected clearance rates by subsetting cases by crime types and estimating the same model (as reported in Table 5 and graphed in Figure 2). Even though Figure 2 suggests there are significant CCTV effect on clearance, when examining individual crime types, this relationship often does not hold. Theft is the only crime types which show more increase of clearance rate in the targeted areas (within 500ft) after 
CCTV installation than other areas beyond CCTV coverage. The plots subsetted by crime type indicates that the CCTV effects on clearance are dominated by thefts which have the largest number of cases. Note that each plot has a different scale on clearance rate. While each plot shows varying patterns, when examining the differences in the probabilities, the confidence interval often covered 0 , suggesting the differences are not statistically significant.

\section{[Figure 4 goes about here]}

Lastly, we estimated the overall expected increases in cleared cases of theft attributable to the installation of CCTV cameras. The left of Figure 5 represents predicted difference of clearance probabilities for thefts within the range of $1500 \mathrm{ft}$ from CCTVs. Each dot represents the increase of clearance probability for each case which occurred after installation of CCTVs, not all theft cases. The increase of clearance probability is calculated by subtracting the hypothetical clearance probability had a camera not been installed from the originally estimated probability. The right of Figure 5 shows the cumulative difference of clearance probability which are summed in order of CCTV distance. In other words, the graph represents the total number of estimated extra theft clearance by installing CCTVs. Within $500 \mathrm{ft}$ from CCTVs, the increase of cumulative clearance probability is steeper than the increase beyond its range. At $500 \mathrm{ft}$, the cumulative difference reaches about 141 (out of 5,012 theft cases within that distance). At 1,500 ft, the cumulative number of additional cases cleared is 277 (out of 15,380 cases within that distance). It means that, among the cases in the range with CCTV installation, our estimates suggest the cameras resulted in an increase of 277 case clearances. Given that this estimate includes the effects surrounding 329 cameras over the study area, this suggests clearances around cameras are not likely to justify the marginal costs of the cameras in this sample.

[Figure 5 goes about here]

\section{Discussion and Conclusions}

This research has explored the relationship between CCTV installation and clearance rates in crime. Several findings suggest some promising uses of a CCTV as an investigative tool which enhances crime clearance. Relative to what clearance rates were before cameras were installed, CCTV's appeared to increase clearances of crimes by around $2 \%$. Given that the vast majority of clearances in the Dallas data are due to arrests, this points to how CCTV technology can be instrumental in improving the administration of justice. However, this effect appears to be mostly limited to thefts, and decays by around 500 feet. Given 
that thefts have a much lower cost to society than more serious crimes (Hunt, Saunders, and Kilmer, 2019), this calls into question whether CCTVs, as used in Dallas, are worth their cost.

In relation to theory, we find as expected that the effect of clearances decays after a short distance. While we do not have information on the viewsheds of individual cameras, this suggests that creating buffers around cameras may not be the most appropriate means of testing the efficacy of the cameras, which may also extend to the analysis of crime reductions as well. This approach, assigning crime incidents to cameras based on the distance to the nearest camera, does not take into account how different cameras may additively increase the probability of clearance (Ratcliffe \& Groff, 2019). We suspect though this additive effect is small, and that the diminishing marginal returns of having saturated cameras likely further hinders their cost-effectiveness in practice, even if there are some additive benefits of having multiple cameras cover the same locations.

We also find that increases in clearances were not uniform across all crime types, but were mostly limited to thefts. Given we are simply examining overall clearance trends, and do not have access to additional data (such as detective utilization of footage), it is difficult to unpack why it is the case that clearance increases were limited to thefts. Given more serious crimes likely are devoted more detective resources to begin with (Cook et al., 2019), it may be the case that CCTV only are effective in moving the needle on cases with an initial low probability of clearance. In terms of crimes like burglary, which also have a low clearance rate in Dallas, it may be that public CCTV are more optimally placed to detect public activity in more commercial areas, thus limiting their utility for residential burglaries (but still should be potentially useful for commercial burglaries).

In terms of practical policy considerations, given that Dallas has already invested in the CCTV technology, it may be the case that even with only the small increases in theft clearances, simply maintaining the cameras may be worth the cost. (We do not have estimates of how much it costs to maintain the cameras over time.) However, if Dallas was considering installing more cameras, they need to consider both how many potential crimes the camera may capture, the nature of the types of crimes nearby the camera, and the current solvability of those crimes.

For example, while it seems unlikely that the current 329 cameras are cost-effective, since we estimated they only resulted in an additional estimated 277 theft cases cleared, it may be that some cameras are more effective than others. Like hot spots policing, a camera may have a greater marginal effect if it is placed in an area with more thefts, or an area that previously had lower case clearance rates. Given that other research has found that cameras are more effective in certain areas based on local characteristics (Lim \& Wilcox, 2017; Piza et al., 2014), this also suggests a more targeted spatial approach is one avenue to improve efficacy of the cameras. So not only may camera placement be more optimal based on both the number of potential crimes they capture in their viewshed, but can be based on the local spatial 
characteristics surrounding the cameras. We did uncover some variability in the spatial random effect at the block group level, suggesting that CCTV may be more slightly more effective in certain neighborhoods (Jang et al., 2018). One limitation of the study is that we did not consider micro level impacts of areas in which cameras are situated, which may also influence the clearance rate (Piza et al., 2014).

Limiting the number of cameras also provides a way to potential trade off those concerned over privacy issues. Ultimately having public CCTV results in some loss of privacy relative to no cameras, but that loss will likely be more palatable to the general public if there is evidence that cameras result in additional benefits, which include both overall crime reductions, as well as improving the likelihood that a crime is solved. Future research should attempt to identify those reasonable trade-offs in efficacy given more cameras in place, especially as it relates to surveillance in minority communities (Wheeler, 2019).

Our findings should be understood in light of the limitations of the study. One we have already mentioned, is that we only consider spatial factors beyond the distance to the nearest CCTV to be ancillary to the current analysis. We do find some evidence of spatial structure in the random effect estimates, suggesting that some neighborhood factors may explain the variation in crime clearance. A bigger limitation though is the lack of micro level factors and their mediating or moderating influences on crime clearance rates. Because such land use factors tend to be spatially consistent over long periods of time, we do not believe it is a great threat to the current findings, given that we use a pre-camera installation period as a control. But it could provide for more efficient results in future work, and better inform data-based placement of future cameras.

Another main limitation is the quasi-experimental nature of the design. The location of CCTV in Dallas is not a random variable, they were intentionally placed in particular locations. It is likely the case that such areas were chosen based on the quantity and the nature of crime occurring around those locations, as well as based on the availability of suitable infrastructure (Piza, 2018). The pre-camera installation trends show that cameras had a higher clearance rate than places further away, even before the cameras were installed. While the quasi-experimental pre-post design should take into account those selection effects on estimating the increase in clearance rates, it also suggests that the cameras may have better returns if placed in areas with lower clearance rates to begin with.

A final limitation of the analysis is that we are limited to factors generally available in the administrative data to test for clearance rates. Other work has identified a myriad of other factors, both within control of the police department as well as outside their control, that ultimately affect clearance rates (Roberts, 2008). While it seems unlikely that changes over time in clearances that would make our findings spurious occur in this analysis, it is something that we cannot test with our limited administrative data at hand. But with the large sample we can provide more precise estimates of the overall increase in the clearance rate, which is still pertinent for cost-benefit analysis of the cameras. 
In total, while the results provide some evidence that public CCTV cameras in Dallas increase case clearance rates, they need to be much more targeted to make them reasonable cost-effective tools to increase crime clearances. While our results cannot be generalized to other cities, additional research on the effect of crime clearances will need to be undertaken to determine if the cost of public CCTV can be justified due to increases in case clearances in addition to their modest benefits in reducing crime overall. 


\section{Bibliography}

Ashby, M. P. J. (2017). The value of CCTV surveillance cameras as an investigative tool: An empirical analysis. European Journal on Criminal Policy and Research, 23, 441-459.

Baskin, D., \& Sommers, I. (2010). The influence of forensic evidence on the case outcomes of homicide incidents. Journal of Criminal Justice, 38, 1141-1149.

Baskin, D., \& Sommers, I. (2011). Solving residential burglaries in the United States: The impact of forensic evidence on case outcomes. International Journal of Police Science \& Management, 13, 70-86.

Bell, M. C. (2016). Situational trust: How disadvantaged mothers reconceive legal cynicism. Law \& Society Review, 50, 314-347.

Bennett, T., \& Gelsthorpe, L. (1996). Public attitudes towards CCTV in public places. Studies on Crime and Crime Prevention, 5, 72-90.

Black, D. (1976). The Behavior of Law. New York: Academic Press.

Borg, M. J., \& Parker, K. F. (2001). Mobilizing law in urban areas: The social structure of homicide clearance rates. Law \& Society Review, 35, 435-466.

Braga, A. A., \& Dusseault, D. (2018). Can homicide detectives improve homicide clearance rates? Crime \& Delinquency, 64, 283-315.

Briggs, S., \& Opsal, T. (2012). The influence of victim ethnicity on arrest in violent crimes. Criminal Justice Studies, 25, 177-189.

Bynum, T. S., Cordner, G. W., \& Greene, J. R. (1982). Victim and offense characteristics: Impact on police investigative decision-making. Criminology, 20, 301-318. 
Campbell, D. T., \& Stanley, J. C. (2015). Experimental and quasi-experimental designs for research. Ravenio Books.

Carr, P. J., Napolitano, L., \& Keating, J. (2007). We never call the cops and here is why: A qualitative examination of legal cynicism in three Philadelphia neighborhoods. Criminology, 45, 445-480.

Clarke, R. V. G. (1997). Situational Crime Prevention. Criminal Justice Press Monsey, NY.

Cook, P. J., Braga, A. A., Turchan, B. S., \& Barao, L. M. (2019). Why do gun murders have a higher clearance rate than gunshot assaults? Criminology \& Public Policy, 0. https://doi.org/10.1111/1745-9133.12451

Cordner, G. W. (1989). Police agency size and investigative effectiveness. Journal of Criminal Justice, $17,145-155$.

Coupe, R. T. (2016). Evaluating the effects of resources and solvability on burglary detection. Policing and Society, 26, 563-587.

Coupe, T., \& Kaur, S. (2005). The role of alarms and CCTV in detecting non-residential burglary. Security Journal, 18, 53-72.

Ditton, J. (2000). Public attitudes towards open-street CCTV in Glasgow. British Journal of Criminology, 40, 692-709.

Gelman, A., \& Hill, J. (2006). Data Analysis Using Regression and Multilevel/Hierarchical Models. Cambridge university press.

Gill, M., Bryan, J., \& Allen, J. (2007). Public perceptions of CCTV in residential areas: "It is not as good as we thought it would be." International Criminal Justice Review, 17, 304-324. 
Goold, B. J. (2002). Privacy rights and public spaces: CCTV and the problem of the "unobservable observer." Criminal Justice Ethics, 21, 21-27.

Gottfredson, M. R., \& Hindelang, M. J. (1979). A Study of the behavior of law. American Sociological Review, 44, 3-18.

Harrell, F. E. (2015). Regression modeling strategies: With applications to linear models, logistic and ordinal regression, and survival analysis (Second edition). Cham Heidelberg New York: Springer.

Honess, T., \& Charman, E. (1992). Closed circuit television in public places: Its acceptability and perceived effectiveness. London: Home Office Police Dept.

Hummel, J., \& Wiseman, P. S. (2008). Non-inferiority studies with binary endpoint: Analysis with adjustment for covariates. 20.

Jang, Y., Kim, D., Park, J., \& Kim, D. (2018). Conditional effects of open-street closed-circuit television. International Journal of Law, Crime and Justice, 53, 9-24.

Kirk, D. S., \& Matsuda, M. (2011). Legal cynicism, collective efficacy, and the ecology of arrest. Criminology, 49, 443-472.

Kutateladze, B. L., Lawson, V. Z., \& Andiloro, N. R. (2015). Does evidence really matter? An exploratory analysis of the role of evidence in plea bargaining in felony drug cases. Law and Human Behavior, 39, 431-442.

Lim, H., \& Wilcox, P. (2017). Crime-reduction effects of open-street CCTV: Conditionality considerations. Justice Quarterly, 34, 597-626. 
Lin, P.-H., \& van Gulijk, C. (2014). Cost-benefit analysis of surveillance technologies. In T. Nowakowski, M. Młyńczak, A. Jodejko-Pietruczuk, \& S. Werbińska-Wojciechowska (Eds.), Safety and Reliability: Methodology and Applications (pp. 409-415). CRC Press.

Lippert, R. (2009). Signs of the surveillant assemblage: Privacy regulation, urban CCTV, and governmentality. Social \& Legal Studies, 18, 505-522.

Marsh, L. C., \& Cormier, D. R. (2001). Spline regression models (Vol. 137). Thousand Oaks, California: Sage.

McEwen, T., \& Regoeczi, W. (2015). Forensic Evidence in Homicide Investigations and Prosecutions. Journal of Forensic Sciences, 60, 1188-1198.

Mize, T. (2019). Best practices for estimating, interpreting, and presenting nonlinear interaction effects. Sociological Science, 6, 81-117.

Möllers, N., \& Hälterlein, J. (2013). Privacy issues in public discourse: The case of "smart" CCTV in Germany. Innovation: The European Journal of Social Sciences, 26, 57-70.

Mood, C. (2010). Logistic regression: Why we cannot do what we think we can do, and what we can do about it. European Sociological Review, 26, 67-82.

Morgan, A., \& Dowling, C. (2019). Does CCTV help police solve crime? Trends \& Issues in Crime and Criminal Justice, 1-16.

Nivette, A. E., Eisner, M., Malti, T., \& Ribeaud, D. (2015). The social and developmental antecedents of legal cynicism. Journal of Research in Crime and Delinquency, 52, 270298.

Paine, C. (2012). Solvability factors in dwelling burglaries in Thames Valley. Cambridge: Master's Thesis. 
Phillips, C. (1999). A review of CCTV evaluations: Crime reduction effects and attitudes towards its use. Crime Prevention Studies, 10, 123-155.

Piza, E. L. (2018). The crime prevention effect of CCTV in public places: A propensity score analysis. Journal of Crime and Justice, 41, 14-30.

Piza, E. L., Caplan, J. M., \& Kennedy, L. W. (2014). Is the punishment more certain? An analysis of CCTV detections and enforcement. Justice Quarterly, 31, 1015-1043.

Piza, E. L., Gilchrist, A. M., Caplan, J. M., Kennedy, L. W., \& O’Hara, B. A. (2016). The financial implications of merging proactive CCTV monitoring and directed police patrol: A costbenefit analysis. Journal of Experimental Criminology, 12, 403-429.

Piza, E. L., Welsh, B. C., Farrington, D. P., \& Thomas, A. L. (2019). CCTV surveillance for crime prevention: A 40-year systematic review with meta-analysis. Criminology \& Public Policy, 18, 135-159.

Ratcliffe, J. H., \& Groff, E. R. (2019). A longitudinal quasi-experimental study of violence and disorder impacts of urban CCTV camera clusters. Criminal Justice Review, 0734016818811917.

Ratcliffe, J. H., Taniguchi, T., \& Taylor, R. B. (2009). The crime reduction effects of public cctv cameras: A multi-method spatial approach. Justice Quarterly, 26, 746-770.

Reeve, R. (2018). Confidence interval of difference of proportions in logistic regression in presence of covariates. Statistical Methods in Medical Research, 27, 451-465.

Roberts, A. (2007). Predictors of homicide clearance by arrest: An event history analysis of NIBRS incidents. Homicide Studies, 11, 82-93. 
Roberts, A. (2008). The influences of incident and contextual characteristics on crime clearance of nonlethal violence: A multilevel event history analysis. Journal of Criminal Justice, 36, $61-71$.

Roman, J., \& Farrell, G. (2002). Cost-benefit analysis for crime prevention: Opportunity cost, routine savings and crime externalities. Crime Prevention Studies, 14, 53-92.

Sampson, R. J., Raudenbush, S. W., \& Earls, F. (1997). Neighborhoods and violent crime: A multilevel study of collective efficacy. Science, 277, 918-924.

Shaw, C. R., \& McKay, H. D. (1942). Juvenile delinquency and urban areas. Chicago, II: University of Chicago Press.

Spriggs, A., Argomaniz, J., Gill, M., \& Bryan, J. (2005). Public Attitudes Towards CCTV: Results From the Pre-Intervention Public Attitude Survey Carried Out in Areas Implementing CCTV (No. 635042007-001). American Psychological Association.

Tankebe, J. (2008). Police effectiveness and police trustworthiness in Ghana: An empirical appraisal. Criminology \& Criminal Justice, 8, 185-202.

Taylor, E. (2010). I spy with my little eye: The use of CCTV in schools and the impact on privacy. The Sociological Review, 58, 381-405.

Wells, H., Allard, T., \& Wilson, P. (2006). Crime and CCTV in Australia: Understanding the relationship (p. 193). Queensland, Australia: Centre for Applied Psychology and Criminology: Bond University.

Welsh, B. C., \& Farrington, D. P. (2008). Effects of Closed Circuit Television Surveillance on Crime. The Campbell Collaboration. 
Welsh, B. C., \& Farrington, D. P. (2009). Public area CCTV and crime prevention: An updated systematic review and meta-analysis. Justice Quarterly, 26, 716-745.

Wheeler, A. P. (2019). Allocating police resources while limiting racial inequality. Justice Quarterly, Online First.

Wilson, D., \& Sutton, A. (2004). Watched over or over-watched? Open street CCTV in Australia. Australian \& New Zealand Journal of Criminology, 37, 211-230. 
Table 1: Clearance information

\begin{tabular}{|c|c|c|c|c|c|}
\hline \multicolumn{3}{|c|}{ Cleared } & \multicolumn{3}{c|}{ Not Cleared } \\
\hline Clear by Arrest & $\begin{array}{c}\text { Clear by } \\
\text { Exceptional Arrest }\end{array}$ & Closed/cleared & Open & $\begin{array}{c}\text { Returned for } \\
\text { Corrections }\end{array}$ & Suspended \\
\hline 14,400 & 3,388 & 71 & 1,987 & 3 & 155,997 \\
\hline
\end{tabular}

Table 2: Distribution of distance between a crime location and the nearest CCTV

\begin{tabular}{|c|c|c|c|c|}
\hline Distance & 0 to $500 \mathrm{ft}$ & 500 to $1,000 \mathrm{ft}$ & 1,000 to $1,500 \mathrm{ft}$ & Over $1,500 \mathrm{ft}$ \\
\hline Cases (\%) & $20,062(11.4)$ & $18,625(10.6)$ & $16,166(9.2)$ & $120,993(68.8)$ \\
\hline
\end{tabular}

Table 3: Cases by crime type

\begin{tabular}{|c|c|c|c|c|c|c|c|c|c|}
\hline Type & Murder & Robbery & Assault & Burglary & MVTheft & Theft & Arson & Drug & Weapon \\
\hline Cases & 439 & 14,288 & 6,673 & 38,932 & 27,392 & 84,433 & 796 & 2,426 & 447 \\
$(\%)$ & $(0.2 \%)$ & $(0.1 \%)$ & $(3.8 \%)$ & $(22.1 \%)$ & $(15.6 \%)$ & $(48 \%)$ & $(0.5 \%)$ & $(1.4 \%)$ & $(0.3 \%)$ \\
\hline
\end{tabular}

Table 4: Report Year

\begin{tabular}{|c|c|c|c|c|}
\hline Year & 0 & 1 & 2 & 3 \\
\hline Period & June 2014 May 2015 & June 2015 May 2016 & June 2016 May 2017 & June 2017 May 2018 \\
\hline Cases & 46,966 & 47,578 & 46,012 & 35,290 \\
\hline Clearance & $5,228(11.1 \%)$ & $4,762(10.0 \%)$ & $4,329(9.4 \%)$ & $3,543(10.0 \%)$ \\
\hline
\end{tabular}

Table 5: Logistic regression results predicting the probability of a case clearance $(\mathrm{n}=175,614)$

\begin{tabular}{lrrrr}
\hline & Coefficient & Std.Error & $\begin{array}{r}\text { Odds } \\
\text { Ratio }\end{array}$ & p-value \\
\hline (Intercept) & -2.0963 & 0.0490 & 0.1229 & $<0.001$ \\
Report Year & -0.0386 & 0.0093 & 0.9621 & $<0.001$ \\
Interval to Report Crime & -0.0053 & 0.0010 & 0.9947 & $<0.001$ \\
Post Camera Installation & 0.1654 & 0.0525 & 1.1798 & 0.002 \\
Spline 1 & -0.0032 & 0.0010 & 0.9968 & 0.001 \\
Spline 2 & 0.0085 & 0.0034 & 1.0086 & 0.013 \\
Spline 3 & -0.0068 & 0.0042 & 0.9932 & 0.101 \\
Post* Spline 1 & -0.0033 & 0.0012 & 0.9967 & 0.005 \\
Post* Spline2 & 0.0114 & 0.0040 & 1.0114 & 0.005 \\
Post* Spline3 & -0.0134 & 0.0049 & 0.9867 & 0.006 \\
\hline
\end{tabular}

* Model also includes controls for a random effect for the block group the case occurred in. 


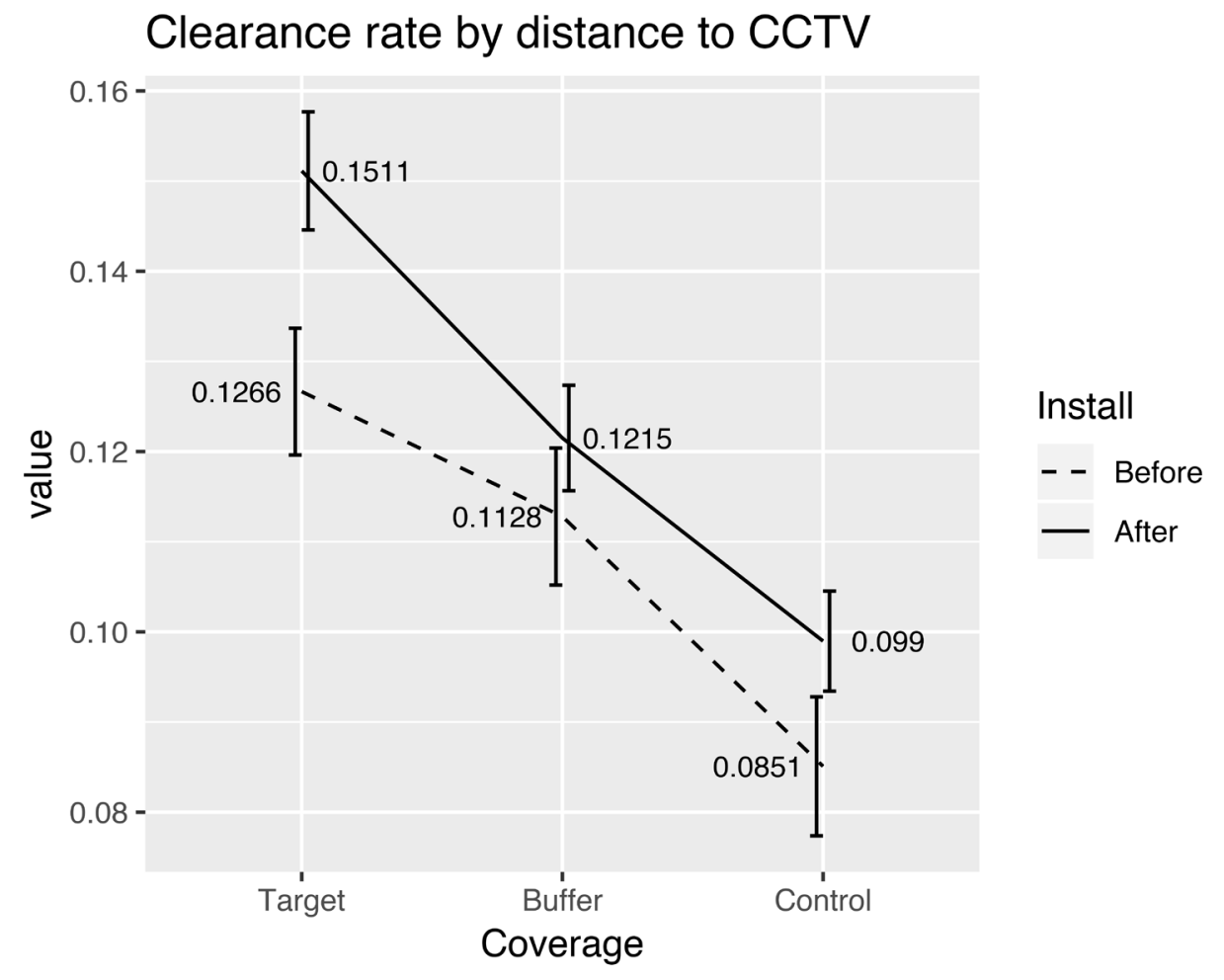

Figure 1: Clearance rates by distance to CCTV
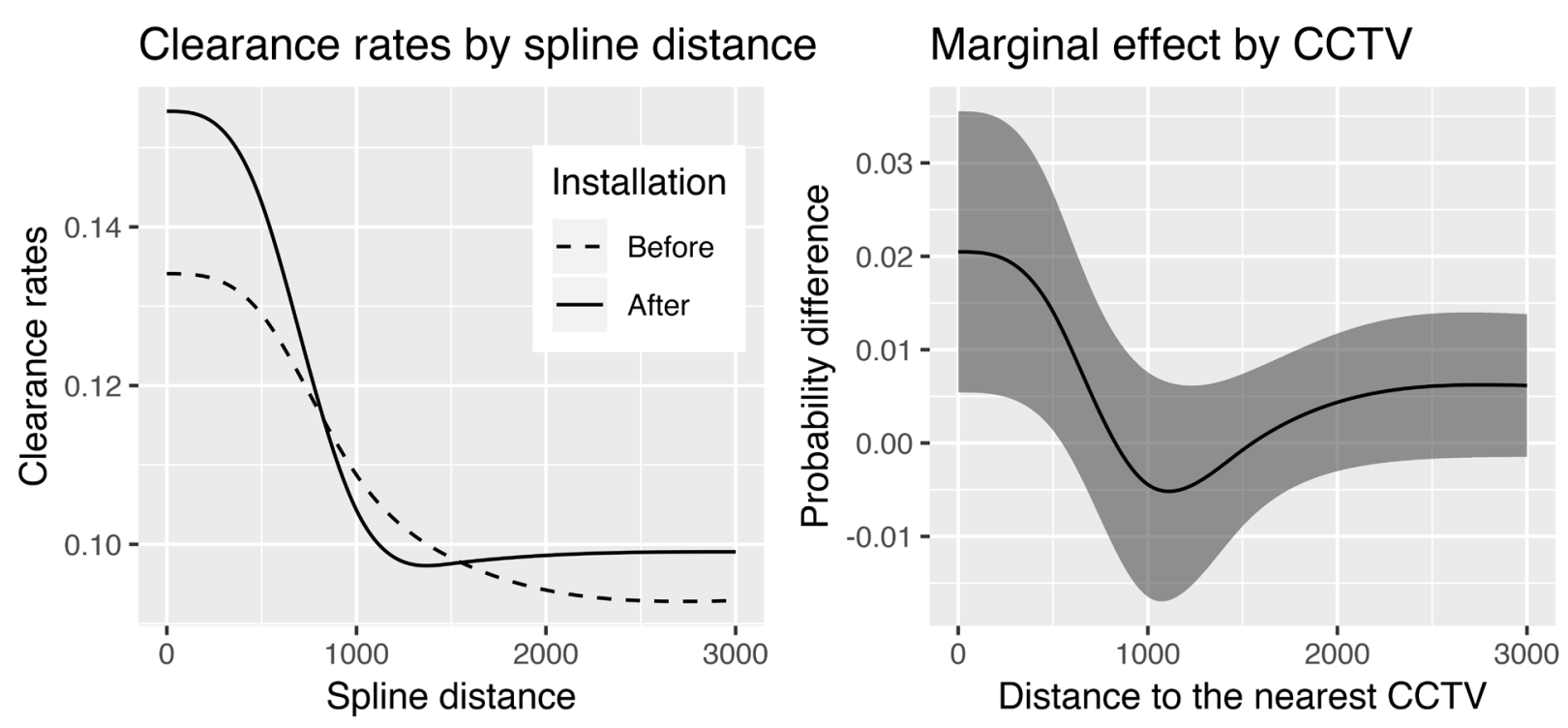

Figure 2: Expected clearance rates and marginal effect of CCTV by spline distance 


\section{Random Effects by Block Groups}

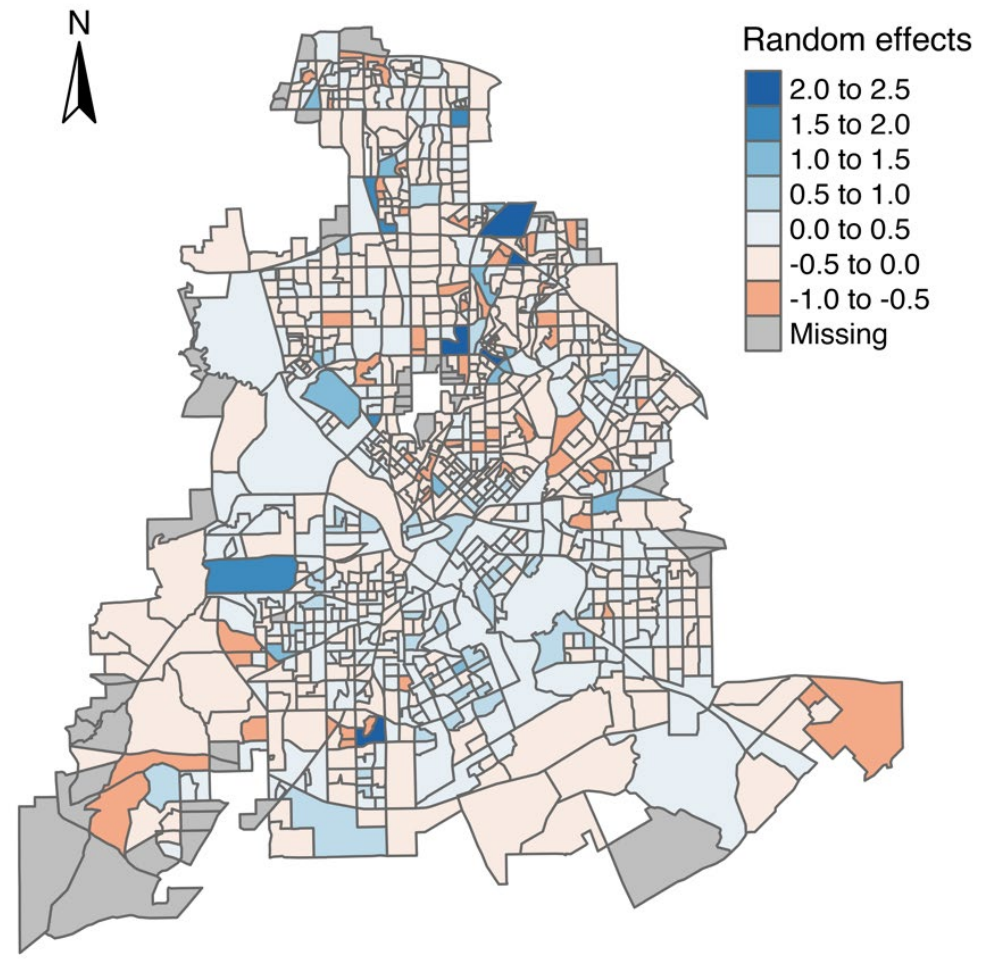

Figure 3: Distribution of random effects 

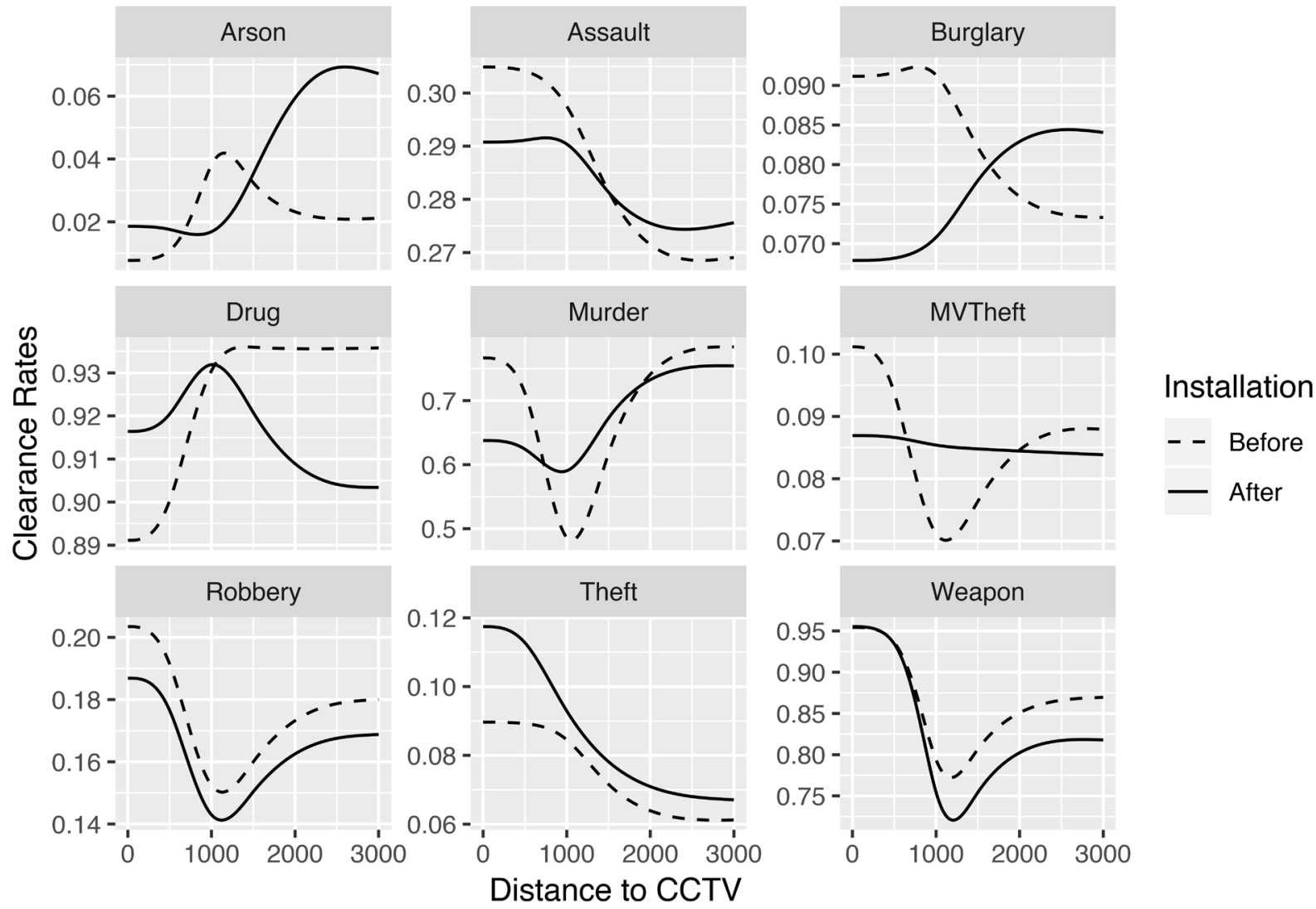

Figure 4: Expected clearance rates by crime types

\section{Predicted difference}

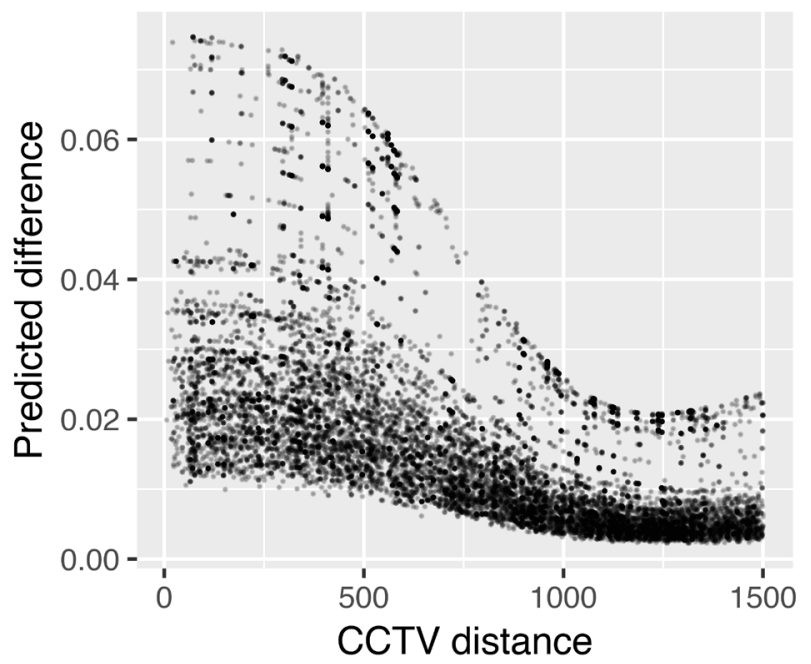

\section{Cumulative sum}

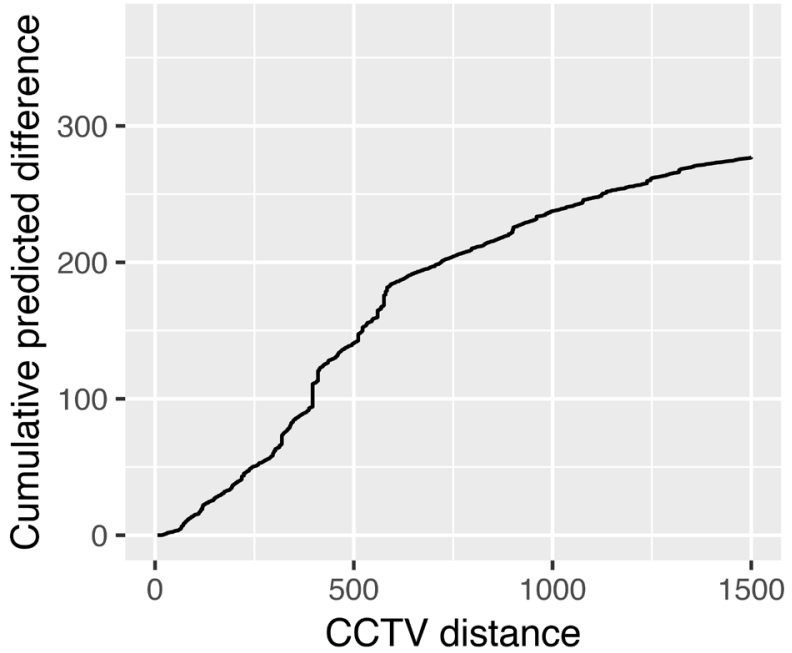

Figure 5: Predicted difference of theft clearance rates and its cumulative effect on the total number of cases cleared 